\title{
Effect of indomethacin on basal and histamine stimulated human gastric acid secretion
}

\author{
R A LEVINE AND E H SCHWARTZEL
}

From the Department of Medicine, State University of New York, Upstate Medical Center, Syracuse, New York, USA

SUMMARY The effect of acute administration of indomethacin over 24 hours on basal and histamine stimulated gastric acid secretion was evaluated in seven normal male volunteers. Augmented histamine tests $(0.015 \mathrm{mg} / \mathrm{kg} / \mathrm{h})$ infused with the antihistamine diphenhydramine hydrochloride $(25 \mathrm{mg} / \mathrm{h})$ were performed before and after pretreatment with indomethacin or matching placebo capsules. The dose of indomethacin was $75 \mathrm{mg}$ (sustained release capsules) taken 12 and 24 hours before and $50 \mathrm{mg}$ taken one hour before a two hour histamine infusion test. Indomethacin enhanced basal gastric secretion from $3.5 \pm 0.5$ to $6.4 \pm 0.6 \mathrm{mmol} / \mathrm{h}(\mathrm{p}<0.01)$ and histamine stimulated secretion from $48 \pm 6$ to $62 \pm 5 \mathrm{mmol} / 2 \mathrm{~h}(\mathrm{p}<0.05)$. Indomethacin significantly inhibited systemic prostaglandin biosynthesis as measured by urinary excretion ( $87 \pm 12$ vs $41 \pm 6 \mathrm{ng} \mathrm{PGE} / \mathrm{g}$ creatinine/h) and the drug increased platelet aggregation time two, five, and six fold, respectively, induced by ADP, collagen, and adrenaline. The data indicate that therapeutic doses of indomethacin augmented basal and secretagogue stimulated gastric acid secretion in control subjects. The enhancement of gastric acid secretion by indomethacin may be because of reduced levels of endogenous prostaglandins. Diminished prostaglandin biosynthesis may play a role in indomethacin induced gastric mucosal damage observed in patients receiving the drug.

Indomethacin, a potent inhibitor of prostaglandin biosynthesis, induces the development of gastric ulcers in animals and possibly gastric and duodenal ulceration in man. The pathogenesis of indomethacin induced gastric mucosal lesions is unclear, but gastric acid may be necessary. ${ }^{1-4}$ The effects of indomethacin on gastric secretion in animals and man remain controversial. Indomethacin induced gastric lesions are inhibited by pretreatment with antacids, anticholinergics, and by vagotomy. ${ }^{1-4}$ Histamine $\mathrm{H}_{2}$ receptor antagonists have been reported to both inhibit ${ }^{2}$ or not prevent gastric lesions due to indomethacin. ${ }^{5}$ In patients and volunteer subjects, indomethacin has been reported to increase,$^{6-9}$ decrease,${ }^{10}$ or produce no change in stimulated gastric acid secretion. ${ }^{11}$ These studies in man were all reported over a decade ago and, unfortunately, prostaglandin measurements were not performed so that the pathogenesis of the

Address for correspondence: Dr Robert A Levine, Department of Medicine, State University Hospital, 750 East Adams Street. Syracuse, New York, 13210. USA.

Received for publication 15 August 1983 alterations or lack of alteration in gastric acid secretion after indomethacin therapy was predicted only from the knowledge of the inhibitory effect of the drug on prostaglandin biosynthesis.

We undertook this study to evaluate the effect of indomethacin on basal and histamine stimulated gastric acid secretion in normal subjects. We used therapeutic concentrations of the drug and documented inhibition of systemic endogenous prostaglandin levels in the biological fluids of these control subjects. We found that indomethacin increased both basal and stimulated gastric acid secretion attributable to the drug.

\section{Methods}

\section{SUBJECTS}

Seven men, mean age 26.7 years (range $18-36$ years) and mean weight $69.8 \mathrm{~kg}$ (range $36-90 \mathrm{~kg}$ ) were studied. They were randomly chosen from a group of medical and graduate students. None had any history suggestive of peptic ulcer disease and all were considered healthy based on a physical 
examination, ECG, and a laboratory screen. This investigation was approved on 15 March 1982 by the Institutional Review Board for the Protection of Human Subjects of the State University Hospital, Upstate Medical Center, and informed written consent was obtained from all subjects.

INDOMETHACIN AND PLACEBO ADMINISTRATION Indomethacin was administered with meals at 12 and 24 hours before the secretory study in the form of a single $75 \mathrm{mg}$ slow release preparation of indomethacin through an osmotic module release system (Indocin SR, Lot No H5282, Merck Sharp \& Dohme, West Point, PA, USA). This capsule allows indomethacin to be released slowly at $6-9 \mathrm{mg} / \mathrm{h}$. This dose was chosen because it is a commonly used regimen for patients with rheumatoid arthritis and provides therapeutic blood levels. A standard $50 \mathrm{mg}$ capsule was also administered (Indocin, Lot No E6210, Merck Sharp \& Dohme, West Point, PA, USA) one hour before nasogastric intubation and the onset of the basal secretory study. Matching placebo capsules were given at the same designated times as indomethacin administration in a randomised, double blind, crossover design. The placebo study was done first in four of seven volunteers. The time interval elapsed between drug and placebo studies ranged from three to six days.

\section{MEASUREMENT OF GASTRIC SECRETION}

Gastric secretion was measured by standard gastric analysis as previously described. ${ }^{12}$ After an overnight fast, the subjects were intubated with a number 16 French nasogastric tube and the tip was adjusted so as to lie in the most dependent portion of the stomach. This position was confirmed fluoroscopically and adequacy of collection was further substantiated by the subsequent recovery after two minutes of at least $80 \%$ of an injected volume of water. With the subject lying semi-reclining on the left side, aspiration was performed by intermittent manual suction. Salivary secretions were removed by suction.

After the stomach was emptied, a saline infusion commenced and basal secretion was collected on ice for four consecutive 15 minute periods. Gastric secretion was then stimulated by a maximal dose of histamine acid phosphate (Eli Lilly and Co), 0.015 $\mathrm{mg} / \mathrm{kg} / \mathrm{h}$ of the base infused intravenously at a constant rate by means of a Harvard pump (Harvard Apparatus Company Inc, Millis, MA, USA). The secretagogue, histamine, rather than gastrin was used as most of the previous studies showing an effect of indomethacin on acid secretion used histamine stimulation, and because our preliminary data in isolated rabbit gastric glands showed enhancement of histamine stimulated acid production by indomethacin (unpublished results). The augmented histamine test was carried out for two hours. The antihistamine diphenhydramine hydrochloride $(25 \mathrm{mg} / \mathrm{h})$ was also infused intravenously. Gastric secretion was collected continuously for two hours after the initiation of histamine stimulation and separated into 15 minute collections. Gastric samples were analysed for volume, $\mathrm{pH}$, and titratible acidity. Gastric acid was titrated with $0 \cdot 1 \mathrm{~N}$ sodium hydroxide to $\mathrm{pH} 7 \cdot 0$ with a $\mathrm{pH}$ meter (Beckman Instruments Inc, Fullerton, CA, USA). The gastric juice was subjectively evaluated for the presence of blood, bile, and mucus.

During the study, subjects were questioned before, during, and after study to determine the possible onset of side effects.

\section{PROSTAGLANDIN SYNTHESIS}

Urine was collected for one hour after ingestion of the $50 \mathrm{mg}$ indomethacin capsule. Samples of blood were taken for platelet aggregation studies at the end of the one hour basal period just before histamine stimulation. Immunoreactive urinary prostaglandins (PGE) were analysed by radioimmunoassay, ${ }^{13}{ }^{14}$ with minor modifications of the methods by Mr Paul Huebner. Platelet aggregation of ADP, collagen, and adrenaline were determined by the method of Sagel et al. ${ }^{15}$ A Chronolog model 330 single channel aggregometer was used. The aggregating solutions were $0.046 \mathrm{mM}$ ADP (Sigma Chemical Company), collagen (Sigma Chemical Company), and $0.1 \mathrm{mM}$ adrenaline (Park-Davis). The collagen was prepared by adding $4 \mathrm{~g}$ of collagen to $100 \mathrm{ml}$ normal saline, ground for 30 minutes and centrifuged at $3000 \mathrm{rpm}$.

\section{STATISTICS}

Calculated secretory measurements after administration of indomethacin for one hour basal or two hours histamine stimulation periods were compared with those obtained after placebo administration. All data were analysed by using Student's $t$ test for paired comparisons (each subject his own control). Data are expressed as mean \pm SEM.

\section{Results}

Gastric secretory studies showed a significant increase in the unstimulated one hour collection of acid secretion after indomethacin pretreatment (Fig. 1). Basal pH decreased from $2 \cdot 1 \pm 0 \cdot 05$ to $1.9 \pm 0.08(\mathrm{p}<0.05)$. Basal volume increased from $99 \cdot 5 \pm 14 \cdot 2 \mathrm{mg} / \mathrm{h}$ to $119.5 \pm 21 \cdot 1 \mathrm{ml} / \mathrm{h}$. 


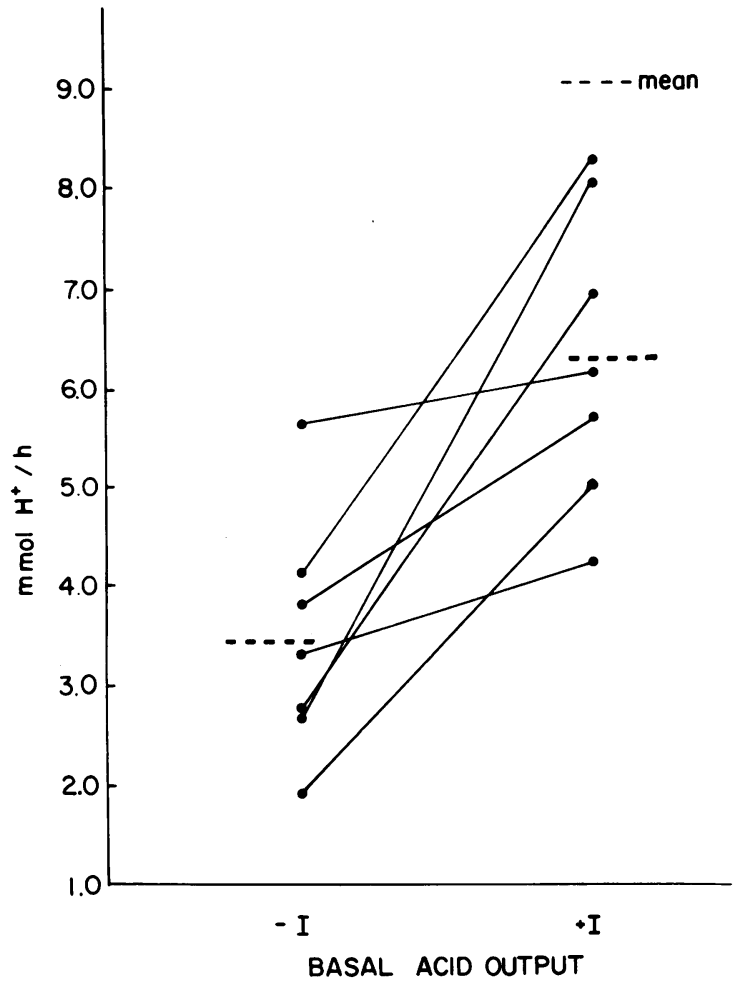

Fig. 1 Effect of placebo (-I) and indomethacin $(+I)$ on one hour basal acid output $(n=7)$. Indomethacin significantly increased basal acid output $(p<0.01)$.

Histamine stimulation after indomethacin administration induced a significant increase in acid secretion whether expressed as peak acid output, maximal output, or as two hours output, as shown in Fig. 2. There was minimal variation during the eight 15 minute collection periods. After histamine stimulation, $\mathrm{pH}$ increased from $1.59 \pm 0.02$ to $1.50 \pm 0.05(\mathrm{p}<0.05)$ and volume output increased from $395.5 \pm 50.4 \mathrm{ml} / 2 \mathrm{~h}$ to $441.7 \pm 47.9 \mathrm{ml} / 2 \mathrm{~h}$ $(\mathrm{p}<0 \cdot 01)$.

The results of urinary prostaglandins and platelet aggregation are shown in Table 1. Indomethacin pretreatment significantly inhibited both urinary E prostaglandins and augmented platelet aggregation induced by ADP, collagen, and adrenaline.

No subjects complained of any deleterious side effects before, during, or after placebo or indomethacin pretreatment or during the augmented histamine test.

\section{Discussion}

Exogenous prostaglandins have been shown to

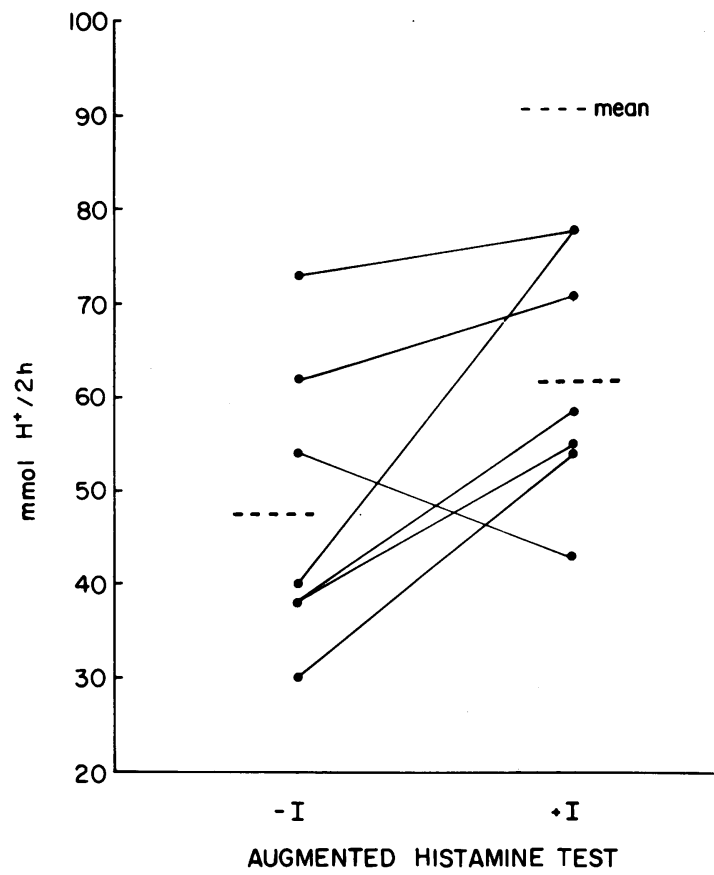

Fig. 2 Effect of placebo $(-I)$ and indomethacin $(+I)$ on two hour histamine stimulated gastric acid secretion $(n=7)$. Indomethacin significantly increased stimulated gastric acid output $(p<0.05)$.

Table 1 Effects of indomethacin on urinary prostaglandins (PGE) and platelet aggregation in seven healthy subjects

Urinary prostaglandins (ng PGE/g creatinine/h)

\begin{tabular}{ll}
\hline$-I$ & $+I$ \\
$87 \pm 12$ & $41 \pm 6(\mathrm{p}<0.01)$
\end{tabular}

Platelet aggregation (sec)

\begin{tabular}{|c|c|c|c|c|c|}
\hline \multicolumn{2}{|l|}{$A D P$} & \multicolumn{2}{|c|}{ Collagen } & \multicolumn{2}{|c|}{ Adrenaline } \\
\hline$-I$ & $+I$ & $-I$ & $+I$ & $-I$ & +1 \\
\hline $\begin{array}{r}112.5 \\
\pm 29.8\end{array}$ & $\begin{aligned} & 251.9 \\
& \pm \pm 50.5 \\
&<0.05)\end{aligned}$ & $\begin{array}{l}49 \cdot 4 \\
\pm 22 \cdot 3 \\
\quad(p\end{array}$ & $\begin{array}{l}312 \cdot 5 \\
\pm 66 \cdot 5 \\
0.025)\end{array}$ & $\begin{array}{l}62 \cdot 0 \\
\pm 42 \cdot 6\end{array}$ & $\begin{aligned} & 492 \cdot 8 \\
\pm & \pm 08 \cdot 0 \\
< & 0 \cdot 01)\end{aligned}$ \\
\hline
\end{tabular}

$-I=$ placebo pretreatment; $+I=$ indomethacin pretreatment. Values are mean \pm SEM. Statistical significance shown as $p$ values. 
inhibit basal and stimulated acid secretion in man and animals. This is the first double blind controlled trial in man correlating the action of indomethacin on gastric acid secretion with diminished prostaglandin synthesis in human biological fluids. We have shown that therapeutic doses of indomethacin enhanced basal and histamine stimulated gastric secretion in normal volunteers, probably by inhibiting systemic prostaglandin biosynthesis.

Previous studies performed in normal subjects and patients with rheumatoid arthritis have generated conflicting data (Table 2). Moreover, no prostaglandin measurements were carried out in any of these studies. The dose and duration of indomethacin administered in these studies is shown in Table 2.

It is possible that indomethacin enhances histamine stimulated acid output by directly decreasing endogenous prostaglandin levels in gastric mucosa. Skoglund et al ${ }^{16}$ previously documented that indomethacin inhibited prostaglandin synthesis in isolated canine parietal cells and showed that pretreatment with $100 \mu \mathrm{M}$ indomethacin abolished the inhibitory effects of the prostaglandin precursor, arachidonic acid, on histamine stimulated acid secretion in this system. Similarly, we have observed in an isolated rabbit fundic gland preparation that indomethacin increased histamine stimulated acid secretion threefold (unpublished results) using the same concentration of indomethacin $(100 \mu \mathrm{M})$ as Skoglund et $a l^{16}$ which, in our preparation, inhibited glandular prostaglandin synthesis by an average of $74 \% .{ }^{17}$
Rask-Madsen and Bukhave ${ }^{18}$ have shown that $25 \mathrm{mg}$ of indomethacin given three times daily reduced gastric juice $\mathrm{PGE}_{2}$ levels by $60 \%$ in two patients with gastric hypersecretion associated with a variant of Menetrier's disease (Stempien's type). The effects on the patients' gastric acidity were not reported.

Regulation of gastric acid secretion and maintenance of the structural and functional integrity of the gastric mucosal barrier may be influenced by local production of prostaglandins in the stomach. ${ }^{19} 20$ Whether or not gastric acid is necessary in the pathogenesis of indomethacin induced gastric mucosal lesions is uncertain. In animals, Whittle ${ }^{2}$ and Okabe et $a l^{3}$ observed that indomethacin induced gastric lesions were inhibited in the presence of the $\mathrm{H}_{2}$ receptor antagonists metiamide and cimetidine, but metiamide did not prevent gastric erosions attributable to indomethacin in studies by Bolton and Cohen. ${ }^{5}$ In animals there is controversy whether or not gastric acid secretion is modified by indomethacin pretreatment. Nicoloff $\mathrm{f}^{21}$ found that indomethacin induced a significant decrease in canine gastric acid output while Gerkens et $a l^{22}$ in the dog, and Main and Whittle ${ }^{23}$ in the rat, documented potentiation of pentagastrin stimulated gastric acid secretion.

Clinical reports indicate that non-steroidal antiinflammatory agents including indomethacin induced gastric lesions in patients with rheumatic disease ${ }^{24}$ Our data would suggest that indomethacin may play a role in gastric mucosal damage as a result of the enhanced gastric acid output brought about

Table 2 Reported actions of indomethacin (I) on human gastric acid secretion stimulated by histamine (H) or pentagastrin $(P G)$

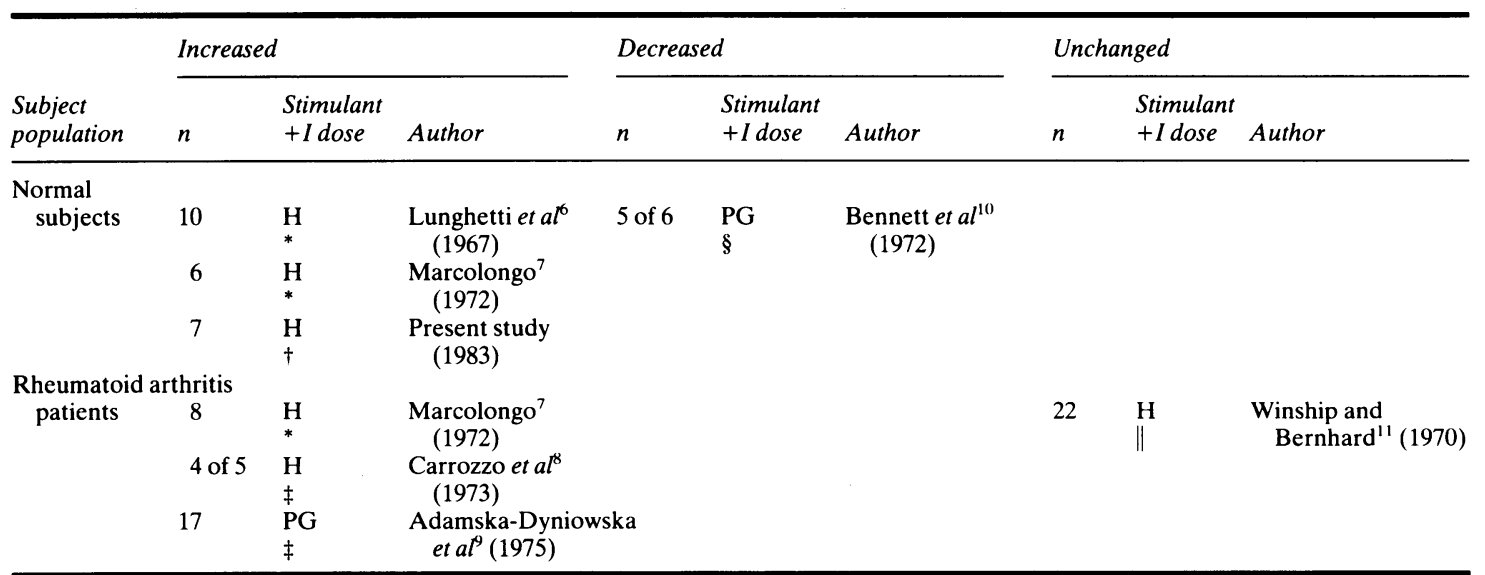

$\mathbf{n}=$ number of individuals reported.

I dose: ${ }^{*} 190-300 \mathrm{mg} /$ day $\times 25$ days; $+200 \mathrm{mg} /$ day $; \ddagger 50-150 \mathrm{mg} /$ day $\times 1-2$ weeks; $§ 200 \mathrm{mg}$ rectal suppositories; $\| 75-100 \mathrm{mg} / \mathrm{day} \times 4$ weeks. 
by cyclooxygenase inhibition in the parietal cell. We have not excluded the possibility that indomethacin may affect gastric acid secretion by a mechanism other than reduction in gastric mucosal prostaglandin levels. Indomethacin may have actions other than cyclooxygenase inhibition alone. Arachidonic acid may be shunted into the lipooxygenase pathway and the metabolites - for example leukotrienes could conceivably influence gastric acid secretion.

Whether or not the gastric mucosal lesions induced in man during treatment with non-steroidal anti-inflammatory agents are in part because of a gastric hypersecretory state or solely because of alterations in cytoprotection is unclear. Further studies of patients at risk will be required to elucidate the role of each of these two possible underlying mechanisms.

We thank Susan Petokas, Autumn Starr, Deborah Patchin, and Sandra Markowitz for their technical assistance. This study was supported by a grant (RR-229) from the General Clinical Research Centers Program of the Division of Research Resources, National Institutes of Health, Bethesda, MD, USA.

\section{References}

1 Lee YH, Mollison KW, Cheng WD. The effects of anti-ulcer agents on indomethacin-induced gastric ulceration in the rat. Arch Int Pharmacol Ther 1971; 192: 370-7.

2 Whittle BJR. Relationship between the prevention of rat gastric erosions and the inhibition of acid secretion by prostaglandins. Eur J Pharmacol 1976; 40: 233-9.

3 Okabe S, Tabata K, Ishihara Y, Kunimi H, Izumi K, Uchida $\mathrm{N}$. Irritative activity of anti-inflammatory agents, betamethasone 17, 21-diproprionate, or indomethacin on the gastrointestinal tract in rats and dogs. Folia Pharmacol Jpn 1978; 74: 774-81.

4 Kasuya Y, Urushidani T, Okabe S. Effects of various drugs and vagotomy on indomethacin-induced gastric ulcers in the rat. Jpn J Pharmacol 1979; 29: 670-3.

5 Bolton JP, Cohen MM. The effect of prostaglandin $E_{2}$, 15-methyl prostaglandin $E_{2}$ and metiamide on established canine gastric mucosal barrier damage. Surgery 1979; 85: 333-8.

6 Lunghetti R, Bianco G, Marcolongo R, Carcassi A. Effetti dell'indomethacin sulla funzionalita gastrica (Effect of indomethacin on gastric function). Settim Med 1967; 55: 1339-53.

7 Marcolongo R. Effetti collateral indesiderati dell'indomethacin (Undesirable side effects on indomethacin). Clin Ter 1972; 60: 343-53.

8 Carrozzo M, Panella C, Loizzi P. Tollerabilita gastrica di un nuovo preparato antireumatico (Gastric tolerance of a new antirheumatic preparation). Minerva Med 1973; 64: 2507-10.
9 Adamska-Dyniewska H, Bala T, Goch JH, Kowalczyk L. Wplyw leczenia indometacyna na wydzielanie electrolitow, bialka calkowitego, mukoproteidow 1 kwasu sialowego $w$ tresci zoladkowej (The effect of indomethacin treatment on secretion of electrolytes, total protein, mucoproteins and sialic acid in gastric juice). Wid Lek 1975; 28: 1117-21.

10 Bennett A, Stamford IF, Unger WG. Prostaglandin $\mathrm{E}_{2}$ and gastric acid secretion in man. $J$ Physiol 1973; 229: 349-60.

11 Winship DH, Bernhard GC. Basal and histaminestimulated human gastric secretion: lack of effect of indomethacin in therapeutic doses. Gastroenterology 1970; 58: 762-5.

12 Levine RA, Schwartzel EH Jr, Backman S, Talev JN. Gastric cyclic nucleotide concentration in health and disease: response to secretogogues and role of circulating gastrin and intragastric secretion. Gastroenterology 1977; 73: 737-45.

13 Dray F, Charbonnel B, MacLouf J. Radioimmunoassay of prostaglandins $E_{\alpha}, E_{1}, E_{2}$ in human plasma. Eur J Clin Invest 1975; 5: 311-8.

14 Christensen P, Leyssac PP. A specific radioimmunoassay for $\mathrm{PGE}_{2}$, using an antibody with high specificity and a sephadex LH-20 microcolumn for the separation of prostaglandins. Prostaglandins 1976; 11: 399-401.

15 Sagel J, Colwell JA, Crook L, Laimins M. Platelet aggregation in early diabetes mellitus. Ann Intern Med 1975; 82: 733-8.

16 Skoglund ML, Nies AS, Gerber JG. Inhibition of acid secretion in isolated canine parietal cells by prostaglandins. J Pharmacol Exp Ther 1982; 220: 371-4.

17 Levine RA, Kohen KR, Schwartzel EH Jr, Ramsay CE. Prostaglandin $E_{2}$-histamine interactions on cAMP, cGMP, and acid production in isolated fundic glands. Am J Physiol 1982; 242: G21-6.

18 Rask-Madsen J, Bukhave $\mathrm{K}$. Inhibitors and gastrointestinal function. In: Ramwell P, ed. Prostaglandin synthetase inhibitors: new clinical applications. New York: Alan R Liss Inc, 1980: 375-96.

19 Robert A, Nezmis JE, Lancaster C, Hanchar AJ. Cytoprotection by prostaglandins in rats. Prevention of gastric necrosis produced by alcohol, $\mathrm{HCl}, \mathrm{NaOH}$, hypertonic $\mathrm{NaCl}$, and thermal injury. Gastroenterology 1979; 77: 433-43.

20 Robert A. Cytoprotection by prostaglandins. Gastroenterology 1979; 77: 761-7.

21 Nicoloff D. The effect of Indocin (indomethacin) on gastric secretion, parietal cell population and ulcer provocation in the dog. [Abstract] Gastroenterology 1967; 52: 1111.

22 Gerkens JF, Shand DG, Flexner C, Nies AS, Oates JA, Data JL. Effect of indomethacin and aspirin on gastric blood flow and acid secretion.J Pharmacol Exp Ther 1977; 203: 646-52.

23 Main IM, Whittle BJR. Investigations of the vasodilator and antisecretory role of prostaglandins in the rat gastric mucosa by use of non-steroidal antiinflammatory drugs. Br J Pharmacol 1975; 53: 217-24.

24 Silvoso GR, Ivey KG, But JH et al. Incidence of gastric lesions in patients with rheumatic disease on chronic aspirin therapy. Ann Intern Med 1979; 91: 517-20. 